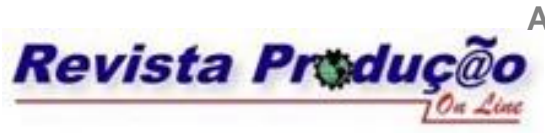

Associação Brasileira de Engenharia de Produção - ABEPRO

Universidade Federal de Santa Catarina - UFSC

www.producaoonline.org.br

ISSN 1676 - 1901 / Vol. IX/ Num.IV/ 2009

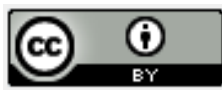

\title{
SUSTENTABILIDADE E RESPONSABILIDADE SOCIAL: PROPOSTA DE MODELO DE DIAGNÓSTICO SOCIOAMBIENTAL BASEADA EM PESQUISA EMPÍRICA
}

\section{SUSTAINABILITY AND ACCOUNTABILITY: PROPOSAL OF SOCIAL AND ENVIRONMENTAL DIAGNOSTIC MODEL BASED IN EMPIRICAL SURVEY}

\author{
Takeshy Tachizawa \\ Doutor em Administração \\ Fundação Getulio Vargas \\ e-mail: usptakes@uol.com.br
}

\section{Resumo}

O trabalho apresenta uma arquitetura de dados socioambientais para diagnóstico das organizações em termos de sustentabilidade econômica. É proposto um modelo de base de dados de indicadores socioambientais, fundamentado em pesquisa empírica, desenvolvida pelo método da grounded theory. A ênfase da grounded theory é o aprendizado a partir dos dados (interativa e indutiva), e não a partir de uma visão teórica existente (dedutiva). Tais indicadores, além de refletir o estágio de sustentabilidade em que se encontra a empresa analisada, subsidiariam o mapeamento socioambiental dos diferentes segmentos econômicos do universo empresarial brasileiro. O modelo proposto, não-prescritivo, sugere que na gestão socioambiental da cadeia produtiva de uma empresa, sejam adotados enfoques distintos de sustentabilidade para os diferentes tipos de organizações que, em razão de seu ramo de negócios, sofrem efeitos diferenciados.

Palavras-chave: sustentabilidade; arquitetura de dados socioambientais; gestão socioambiental; indicador de desenvolvimento socioambiental; cadeia produtiva sustentável.

\footnotetext{
Abstract

It presents an architecture of data for diagnosis of social and environmental of organizations in terms of economic sustainability. It proposed a model of the database of indicators of social
} 
differentiation of costs, based on empirical research, developed the method grounded theory. The emphasis of grounded theory is that learning from the data (interactive and inductive), and not from a theoretical vision existing (deductive). Such indicators, and reflect the stage of sustainability where the company tested, sinalyzing the mapping of different socio economic segments of the Brazilian business universe. The architecture, structured with the support of information technology resources would allow the planning decisions inherent in the management of social costs of their production chain.

Keywords: sustainability, architecture of data sustainability, accountability management; accountability indicator; sustainable supply chain

\section{INTRODUÇÃO}

A responsabilidade socioambiental corporativa, na trilha de desastres socioambientais envolvendo organizações globalizadas, ganha importância como instrumento de gestão empresarial para evitar riscos econômicos. Os clientes, neste novo cenário econômico, têm expectativas de interagir com organizações que sejam éticas, tenham boa imagem institucional no mercado, e que atuem de forma ecologicamente responsável. Neste ambiente, emerge a questão da sustentabilidade, que enfatiza o compromisso dos gestores junto aos stakeholders, como instrumento de gestão para a otimização econômica da organização.

Neste contexto, foram analisados os fatores de influência da sustentabilidade nas empresas brasileiras e as possibilidades do uso de indicadores socioambientais, proposta do presente trabalho. Foram abordadas as atividades econômicas exercidas pelas organizações, através de pesquisa empírica, em seus diferentes ramos de negócios, relacionando-as com suas características de sustentabilidade.

Como decorrência desta análise, estabeleceu-se uma metodologia para o diagnóstico socioambiental com enfoque diferenciado para cada tipo de organização do cenário empresarial brasileiro. Este diagnóstico permitiu estruturar um tipo de indicador de desenvolvimento socioambiental (IDS) que levasse em conta as peculiaridades existentes nas empresas em função do seu setor econômico de atuação. Com isso, pode-se constituir uma 
referência para análise do passivo e ativo socioambiental, que seriam singulares aos efeitos da sustentabilidade, intrínsecos a cada setor econômico.

O princípio que serviu de base para a composição do IDS, foi fundamentado na avaliação do desenvolvimento na empresa, não do ponto de vista do crescimento econômico, mas pelo prisma de outras dimensões, capazes de interpretar a sustentabilidade de suas ações empresariais. Estas dimensões, em sintonia com o potencial crescimento profissional dos colaboradores da empresa, na medida em que convivem com saudáveis práticas de qualidade de vida, constituiu o embasamento filosófico deste trabalho, quais sejam: cidadania corporativa; transparência; governança corporativa; e capital humano.

O IDS, portanto, objetivou o desenvolvimento de uma métrica que espelhasse o estágio evolutivo da organização em termos socioambientais, em seu contexto interno e externo.

As razões que justificariam seu uso como instrumento de gestão pelas empresas não são apenas decorrentes de aderência à legislação vigente, mas, principalmente, em função das possibilidades de direcionar as decisões de gestão econômica de forma convergente com os objetivos da sustentabilidade empresarial.

\section{FUNDAMENTAÇÃO TEÓRICA}

Problemas como poluição, falta de segurança, corrupção, má gestão dos recursos públicos, aética, e tantos outros entraves institucionais e organizacionais, perpassam toda a história da humanidade desde o surgimento dos primeiros agrupamentos urbanos até os tempos atuais (TACHIZAWA e ANDRADE, 2008). Para Henderson (2001), tal perspectiva tem se acentuado no mundo contemporâneo, como decorrência das mutações ocorridas na escala das crenças e valores do ser humano, delineadas pela Revolução Industrial.

Essas mudanças evoluíram para os tempos atuais como responsabilidade social. Esta, entendida como uma forma de gestão, que se define pela relação ética e transparente da organização com os públicos com os quais ela se relaciona. E, pelo estabelecimento de metas empresariais, compatíveis com o desenvolvimento sustentável, preservando recursos ambientais e culturais para as gerações futuras (INSTITUTO ETHOS, 2008). Este envolvimento empresarial em ações sociais na comunidade começou na forma de ações 
voluntárias das empresas, focando problemas sociais até atingir os patamares atuais de sustentabilidade empresarial (BRONN e VRIONI, 2001).

Uma das principais características presentes nesse cenário é a mudança no conceito do que é importante, do que tem valor, das metas a serem atingidas e dos meios de avaliação (indicadores) do progresso coletivo em direção a essas metas (HENDERSON, 2001). Estes instrumentos de mensuração irão desempenhar diferentes papéis sob vários aspectos, pois orientam o campo econômico e social, sendo indispensáveis aos pesquisadores e empresários, além de contribuir para que o cidadão possa ter diferentes visões do que está ocorrendo na sociedade (BESSERMAN, 2003).

Para a Organization for Economic Co-operation and Development - OECD (2008), um indicador deve ser entendido como um parâmetro, ou valor derivado de parâmetro, que aponta e fornece informações sobre o estado de um fenômeno com uma extensão significativa. Evans e Würster (2000) prescreveram a importância estratégica da informação que deixou de ser apenas uma ferramenta de controle para os gestores e tomou posição de um recurso básico que justifica sua utilização como base para a formulação de indicadores, principalmente para suporte ao processo decisório (LAUDON e LAUDON, 2000; RAYPORT e JAWORSKI, 2001).

O Programa das Nações Unidas para o Desenvolvimento (PNUD, 2008) publicou o Índice de Desenvolvimento Humano (IDH) com o propósito de desafiar as estreitas definições econômicas de progresso que compõem o Produto Interno Bruto (PIB). O IDH incorpora, além dos indicadores econômicos, os sociais, as estatísticas sobre os índices de alfabetização, a média da expectativa de vida e o poder de compra.

O IDH tornou-se, pois, o mais importante instrumento de medida e de comparação da condição de vida não só de países, mas também de espaços menores como estados e municípios (BESSERMAN, 2003). A Comissão de Desenvolvimento Sustentável da ONU publicou, em 1996, o documento, Indicadores de Desenvolvimento Sustentável: estrutura e metodologia, apresentando um conjunto de indicadores econômicos, sociais e ambientais (IBGE, 2008).

Neste cenário se insere a ISO14000, para meio ambiente e, mais recentemente, a ISO16000, AA1000 e SA8000 (TACHIZAWA, 2009), como certificações sociais com o 
objetivo de atestar que a organização, além de ter procedimentos internos corretos, participa de ações não lucrativas. A Organização para a Cooperação e o Desenvolvimento Econômico - OCDE recomenda que as organizações, públicas e privadas, adotem princípios focados na transparência de suas ações. O balanço social se insere neste cenário de transparência e disseminação de informações junto aos seus diferentes públicos (RAYNARD e FORSTARTER, 2002).

O Instituto Ethos de Responsabilidade Social (ETHOS, 2008) sugere um padrão de balanço social, que explicita os impactos da atividade da empresa na sociedade e evidencia o relacionamento com os seus diferentes públicos. O modelo Ethos considera, ainda, a apresentação do relatório sugerido pelo Instituto Brasileiro de Análises Sociais e Econômicas (IBASE, 2008), e constitui uma alternativa de evidenciação das atividades empresariais através de balanço social.

A Bolsa de Valores de São Paulo (BOVESPA, 2008), neste cenário, e face ao crescente interesse dos investidores em migrar para os portfólios verdes, em resposta à demanda de bancos, fundos de pensão e gestores de recursos, organizou um índice de responsabilidade social e sustentabilidade (índice de sustentabilidade empresarial - ISE), baseado no Dow Jones Sustainability Indexes da Bolsa de Nova York - DJSI. Este indicador global de sustentabilidade monitora o desempenho financeiro das companhias de capital aberto.

O DJ-SI, na sua composição, pondera a importância da integração dos fatores econômicos, ambientais e sociais na estratégia da empresa e avalia aspectos como inovação tecnológica, governança corporativa, interesse dos investidores, expectativas dos públicos de interesse, liderança e capacidade de resposta às mudanças sociais (TACHIZAWA e ANDRADE, 2008).

Nesse sentido, torna-se fundamental aprimorar o processo de armazenamento e recuperação de informações, razão pela qual Draper e Dunlop (2008), procuraram desenvolver métodos de identificar e acessar informações relevantes segundo a percepção dos usuários de nível estratégico nas empresas. Vindo ao encontro disso, emerge o conceito de gerenciamento de desempenho corporativo (corporate performance management - CPM), cuja questão-chave não é só medir, mas projetar um processo que contemple decidir quais 


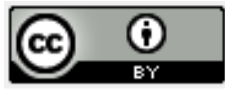

necessidades podem ser medidas, como e quando (BUYTENDIJK, WOOD e GEISHECKER, 2004).

E nesse contexto, motivado pela existência de uma lacuna entre o que os gestores necessitam em termos de sustentabilidade e o que ocorre no dia-a-dia das operações empresariais, foi desenvolvido o presente trabalho.

\section{METODOLOGIA DA PESQUISA}

Os dados da pesquisa empírica, desenvolvida ao longo do ano de 2008, e obtidos segundo uma perspectiva indutiva, foram base do presente estudo. Nesta pesquisa, foi utilizado o método grounded theory (GLASER e STRAUSS, 1967) que é uma modalidade de pesquisa que busca gerar novas teorias através de conceitos, categorias e propriedades.

A ênfase da grounded theory é o aprendizado a partir dos dados (interativa e indutiva), e não a partir de uma visão teórica existente (dedutiva). A maior diferença entre grounded theory e outros métodos de pesquisa é seu foco específico no desenvolvimento da teoria, através de uma contínua interdependência entre a coleta de dados e a análise.

É um método que provê uma estrutura metodológica freqüentemente ausente em outras abordagens, tanto qualitativa como quantitativa, sem sacrificar a flexibilidade ou o rigor.

A grounded theory foi desenvolvida no âmbito da pesquisa em ciências sociais, enfatizando a descoberta indutiva de teorias a partir dos dados analisados sistematicamente. Outros autores desenvolveram e debateram o método (GLASER, 1998; GLASER e HOLTON, 2004; STRAUSS e CORBIN, 1994; STRAUSS e CORBIN, 1997) reafirmando que: (a) a proposta principal do método é a construção de teoria, e não somente a codificação e análise de dados; (b) regra geral, o pesquisador não deve definir um quadro conceitual que antecede ao início da pesquisa, como premissa, para garantir que os conceitos possam emergir sem vieses conceituais pré-definidos; (c) a análise e a conceituação são obtidas através do processo de coleta de dados e comparação constante, no qual cada segmento de dados é comparado com construtos existentes, visando enriquecer uma categoria existente, formar uma nova ou estabelecer novos pontos de relação entre categorias. 
O universo desta pesquisa foi o conjunto das maiores organizações do ramo industrial, comercial e de prestação de serviços que atuam na economia nacional (REVISTA EXAME, 2008).

A pesquisa foi desenvolvida ao longo do ano de 2008, com a coleta de dados, através de questionários eletrônicos, encaminhados diretamente aos executivos das 1.000 maiores empresas brasileiras, critério da publicação Melhores e Maiores e das 150 melhores empresas em sustentabilidade (REVISTA EXAME, 2008).

Complementando as respostas dos questionários preenchidos, foram obtidas informações disponibilizadas diretamente nos sites corporativos das mesmas empresas da amostra pesquisada.

Foram considerados, a título de informações adicionais, dados relacionados a balanços sociais e relatórios de sustentabilidade acessados, via Internet, junto às empresas da amostra, para fins de análise complementar. Foram consideradas, também, informações específicas obtidas dos portais corporativos do Instituto Ethos, Ibase, Bovespa, IBGC, Revista Exame, Época e publicações especializadas em negócios.

\section{ANÁLISE DOS RESULTADOS}

Na concepção da arquitetura de dados socioambientais, procurou-se analisar as respostas das 458 empresas que responderam a pesquisa ( $42 \%$ de respostas em relação ao total das 1.150 empresas pré-selecionadas), o que permitiu estabelecer uma compreensão da sustentabilidade empresarial das organizações da economia nacional. Pela aplicação do questionário eletrônico e acesso aos sites das empresas, obtiveram-se dados socioambientais relativos aos setores de atuação. Pelos dados primários coletados, ficou evidenciado que $65,7 \%$ do total das empresas da amostra que responderam ao questionário são indústrias, seguido das empresas de serviços com $21,6 \%$ e, complementarmente, $12,7 \%$ de empresas comerciais.

Para entender metodologicamente a proposta de classificação das organizações em termos de sustentabilidade, considerou-se, inicialmente, uma classificação simples (organizações industriais, comerciais e de serviços), para posteriormente adotar uma tipologia 
mais completa de organizações que são economicamente conectadas entre si no ambiente empresarial brasileiro.

Como empresas do setor industrial, enquadraram-se as organizações relacionadas a atividades vinculadas à siderurgia, ao cimento, ao papel e celulose, ao segmento metalmecânico, à metalurgia, ao segmento automotivo, e a assemelhadas (bens duráveis e de consumo). São aquelas empresas que transformam insumos produtivos (matérias primas em geral) em produtos acabados. Por outro lado, como empresas prestadoras de serviços foram consideradas como tal, aquelas prestadoras de serviços financeiros (bancos, financeiras e corretoras valores e seguros), engenharia, publicidade e propaganda, hospitais, hotelaria e afins. E, como empresas comerciais, foram consideradas aquelas dedicadas ao ramo atacadista e varejista (lojas comerciais, distribuidoras e correlatas).

Outra indagação inserida na pesquisa foi em relação ao foco de atuação da empresa em termos de sustentabilidade, cuja incidência de respostas é evidenciada na Tabela 1.

Tabela 1- Ações socioambientais aferidas na pesquisa

\begin{tabular}{|l|c|c|c|}
\hline \multicolumn{1}{|c|}{ DISCRIMINAÇÃO } & $\underline{\text { SERVIÇOS }}$ & $\underline{\text { INDUSTRIAL }}$ & COMERCIAL \\
Educação & $36,4 \%$ & $44,7 \%$ & $29,5 \%$ \\
\hline Meio ambiente & $11,9 \%$ & $75,8 \%$ & $43,1 \%$ \\
\hline Saúde & $37,8 \%$ & $22,3 \%$ & $35,4 \%$ \\
\hline Ações Comunitárias & $44,3 \%$ & $31,1 \%$ & $49,8 \%$ \\
\hline
\end{tabular}

Fonte: concepção dos autores

Pelas respostas, evidenciou-se uma preponderância de ações de proteção ambiental nas empresas industriais $(75,8 \%)$. Nas demais empresas, serviços $(11,9 \%)$ e comerciais $(43,1 \%)$, notou-se menor ênfase com relação à preservação do meio ambiente. Outras ações sociais e comunitárias (voluntariado, cultura, segurança, inclusão social, portadores de necessidades especiais, criança e adolescente, pessoas da terceira idade e proteção de animais) distribuíramse, com ligeiro destaque aos setores comerciais e de serviços.

As características socioambientais aferidas na pesquisa evidenciaram impactos de sustentabilidade diferenciados para cada tipo de empresa (vide Quadro 1). Os resultados da 


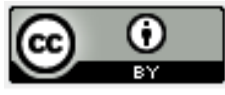

análise destes fatores de influência pesquisados permitiram a identificação de características socioambientais intrínsecas a cada tipo de organização.

Quadro 1: Características socioambientais aferidas na pesquisa

\begin{tabular}{|l|c|c|c|}
\hline \multicolumn{1}{|c|}{ EXIGÊNCIAS E EFEITOS SOCIOAMBIENTAIS } & SERVIÇOS & INDÚSTRIA & COMÉRCIO \\
\hline a) de sustentabilidade na cadeia produtiva & baixa & alta & média \\
\hline b) impacto da produção no meio ambiente & nula & alta & baixa \\
\hline c) impacto do produto no meio ambiente & nula & alta & baixa \\
\hline d) fornecedores observarem requisitos socioambientais & Baixa & alta & média \\
\hline e) normas ambientais ISO14000 & nula & alta & média \\
f) normas responsabilidade social ISO16000 & alta & média & média \\
\hline g) norma segurança no trabalho OHSAS18000 & baixa & alta & média \\
\hline h) publicação sistemática de balanço social (Ethos, & & & \\
Akatu, IBase, Global Report Initiative - GRI, outros) & alta & média & baixa \\
\hline
\end{tabular}

Fonte: Dados coletados pelos autores

De acordo com dados fornecidos pelos respondentes do questionário da pesquisa, evidenciou-se que a utilização de normas de proteção ambiental (ISO14000) e de higiene e segurança no trabalho (OHSAS série 18000), se aplicam essencialmente às empresas industriais. Por outro lado, normas como a ISO16000, são usuais a todas as organizações, com especial ênfase às empresas de serviços financeiros (alta exigência em responsabilidade social), enquanto nas empresas industriais e comerciais constataram-se uma mediana exigência socioambiental, dada as peculiaridades de suas operações empresariais. Essas exigências socioambientais, correlacionadas aos tipos de empresas, são evidenciadas na Figura 1, de acordo com a afinidade dos fatores pesquisados.

Figura 1- Diferenciação das organizações em face de suas características socioambientais 


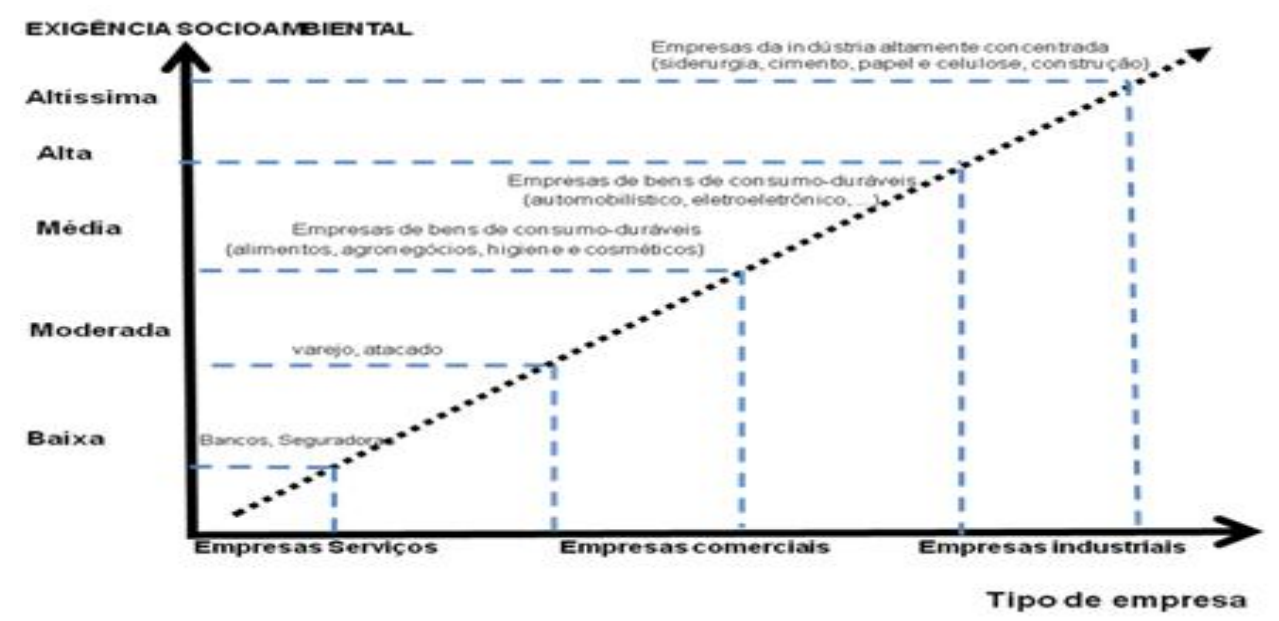

Fonte: Concepção dos autores

Consoante Figura 1 nota-se que a linha horizontal representa o tipo de empresa e na linha vertical o grau dos efeitos potencialmente causados pela organização ao meio ambiente, dada a natureza de suas atividades econômicas, bem como das exigências em termos de ações de responsabilidade social. Analisando os diferentes tipos de organizações, evidenciou-se que as empresas prestadoras de serviços apresentam exigências socioambientais quase que nulas, resumindo suas estratégias às práticas de marketing institucional, em termos de divulgação de balanços sociais e projetos comunitários, implementados nas áreas de: preservação ambiental; educação; segurança; voluntariado; cultura; reciclagem de materiais; e ações correlatas. No outro extremo, têm-se as empresas industriais causadoras, em potencial, de maiores impactos ambientais bem como de exigências de ações de responsabilidade social. São aquelas empresas vinculadas ao segmento de siderurgia, cimento, papel e celulose, energia e similares. Esta categoria de empresas, normalmente, necessita de certificação internacional do tipo selo verde e/ou equivalentes instituídos pela SA8000, AA1000, ISO14000 e congêneres.

Entre estes dois extremos têm-se os outros tipos de empresas (empresas comerciais) que, normalmente, podem adotar estratégias socioambientais compatíveis com o baixo grau de exigências ambientais causados pelos seus processos, e estratégias sociais coerentes com o grau de expectativa da comunidade na qual estão inseridas. 


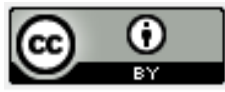

Nos diferentes tipos de empresas, conforme dados coletados na pesquisa (além das empresas de serviços, comerciais e industriais) evidenciou-se que outras categorias de organizações, entre tipo $\mathbf{C}$ a tipo I (vide Quadro 4), como bancos, por exemplo, apresentam impactos ambientais quase que nulos, resumindo suas estratégias socioambientais, praticamente, à divulgação de balanços sociais e projetos comunitários. Ao lado dos bancos têm-se organizações como as instituições de ensino, empresas de serviços especializados que exercem atividades de baixíssimo impacto ambiental enquanto no extremo superior da Figura 1, têm-se as empresas da indústria altamente concentrada, provocadoras de fortíssimos impactos ambientais.

Outra indagação da pesquisa foi quanto à existência de ações relacionadas à responsabilidade socioambiental, cujas respostas dos questionários respondidos pelos gestores das empresas pesquisadas, são evidenciadas no Quadro 2, ilustrado a seguir.

Quadro 2 - Existência de ações relacionadas à responsabilidade socioambiental

\begin{tabular}{|c|c|c|c|}
\hline DISCRIMINAÇÃO DOS FATORES PESQUISADOS & Serviços & Comércio & Indústria \\
\hline Melhoria da qualidade de seus processos, produtos e serviços & & & $\mathrm{X}$ \\
\hline Aumentar a competitividade das exportações & & & $\mathrm{X}$ \\
\hline Atender o consumidor verde & & $\mathrm{X}$ & $\mathrm{X}$ \\
\hline Atender à pressão de organizações ambientalistas & & $\mathrm{X}$ & $\mathrm{X}$ \\
\hline Melhorar a imagem perante a sociedade & $\mathrm{X}$ & $\mathrm{X}$ & $\mathrm{X}$ \\
\hline Reduzir custos dos processos industriais & & & $\mathrm{X}$ \\
\hline Atender exigências de licenciamento/regulamentação & & & $\mathrm{X}$ \\
\hline $\begin{array}{l}\text { Redução emissões de gases causadores do efeito estufa(CO2, metano, } \\
\text { etc.) }\end{array}$ & & & $\mathrm{X}$ \\
\hline Geração de créditos de carbono (de projetos ambientalmente sustentáveis) & & & $\mathrm{X}$ \\
\hline $\begin{array}{l}\text { Comercialização de créditos de carbono advindos da redução da emissão } \\
\text { de gases na cadeia produtiva da empresa }\end{array}$ & & & $\mathrm{X}$ \\
\hline
\end{tabular}

Fonte: Dados coletados pelos autores

Procurou-se, também, coletar dados sobre o relacionamento das organizações com seus fornecedores, conforme evidenciado no Quadro 3. A "não-adoção de trabalho infantil" bem como a existência de trabalho escravo foram questões investigadas junto às empresas pesquisadas quanto à sua postura em relação ao desempenho de seus fornecedores. Tais situações se evidenciaram críticas nas organizações produtora de agronegócios, por exemplo, enquadradas como indústria de bens de consumo não duráveis. 
Quadro 3 - Requisitos exigidos dos fornecedores

\begin{tabular}{|l|l|l|l|}
\hline DISCRIMINAÇÃO DOS FATORES PESQUISADOS & Serviços & Comércio & Indústria \\
\hline Exigência de cadeia produtiva sustentável & \\
\hline \hline Adoção de práticas ambientais & \\
\hline Não-adoção de trabalho infantil & \\
\hline Aplicação da legislação inerente aos portadores de necessidades especiais & & \\
\hline Empresa visita fornecedor para inspecionar sua responsabilidade socioambiental & & \\
\hline Observância dos valores da empresa nos programa de treinamento de fornecedores & $\mathrm{X}$ & $\mathrm{X}$ \\
\hline
\end{tabular}

Fonte: Dados coletados pelos autores

Estas questões abrangeram, desde empresas de baixo efeito socioambiental, como decorrência natural de suas atividades econômicas, com comportamento ético compatível com esta ínfima exigência em termos de responsabilidade social, até empresas do setor altamente concentrado, que adotam processo de avaliação de impactos dos produtos, processos e instalações, que precisa se subordinar às demandas e questões públicas. Os três tipos básicos de organizações, como decorrência de análise, agora detalhada, dos fatores pesquisados (passivo socioambiental) nas empresas da amostra, puderam ser desdobrados em 10 tipos, conforme explicitado no Quadro 4.

Quadro 4 - Tipologia de empresas

Organizações sociais (tipo A): que assume responsabilidades perante a sociedade e toma ações em relação ao exercício da cidadania coerente às suas atividades econômicas. A promoção do comportamento ético também é compatível com seu ramo de negócios de ínfima exigência socioambiental, tais como: cooperativas e associações; ONGs; OSCIPs.

Empresas de serviços (tipo B): que reconhece os impactos causados por seus serviços e processos, apresentando ações isoladas no sentido de minimizá-los. Posicionamento exigido para empresas de prestação de serviços especializados; firmas de arquitetura e engenharia; auditoria e consultoria, software house, escritórios de advocacia e afins.

Empresas comerciais (tipo C): que adota práticas socioambientais para atenuar os potenciais impactos dos produtos comercializados, processos e instalações. Tende a exercer certa liderança em questões de interesse da 


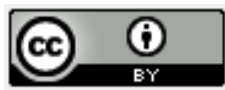

comunidade. Existe envolvimento das pessoas em esforços de desenvolvimento social. Médias e grandes organizações do setor de comércio varejistas e atacadistas e afins.

Instituições financeiras (tipo D): que implementa práticas socioambientais para atenuar os impactos de seus serviços, processos e instalações. A organização promove o comportamento ético. Empresas prestadoras de serviços financeiros; bancos; seguradoras; e empresas de serviços em geral.

Hospitais e Hotelaria (tipo E): que adota práticas socioambientais para atenuar os impactos de seus serviços, processos e instalações. O estímulo à participação das pessoas em esforços de desenvolvimento social é sistemático. Posicionamento exigido para hotéis, hospitais e organizações prestadoras de serviços de lazer e entretenimento.

Empresas de médio efeito socioambiental (tipo F): que implementa práticas socioambientais para atenuar os médios impactos de seus produtos, processos e instalações. A empresa publica balanços sociais e cumpre padrões anteriormente estruturados nos estágios anteriores. Posicionamento, normalmente, exigido para empresas de materiais de construção; do setor automotivo; confecções e têxteis; e higiene e cosméticos.

Indústria de bens de consumo não-duráveis (tipo G): o processo de avaliação dos impactos dos produtos, processos e instalações precisa ser sistematizado, buscando antecipar as questões públicas. A empresa necessita, normalmente, de certificação internacional do tipo selo verde e/ou equivalentes, como: alimentos; agronegócios; e atividades correlatas de alto impacto socioambiental.

Indústria de bens de consumo duráveis (tipo H): o processo de avaliação dos impactos dos produtos, processos e instalações precisa ser sistematizado, buscando antecipar as questões públicas. São empresas que adotam certificação internacional do tipo selo verde e/ou equivalentes, tais como: construção pesada; plásticos e borracha; eletroeletrônicos; metalurgia e atividades correlatas de significativo impacto socioambiental.

Indústrias de alto efeito socioambiental (tipo I): o processo de avaliação dos impactos dos produtos, processos e instalações precisa ser sistematizado, buscando antecipar as questões públicas. A empresa necessita de certificação internacional do tipo selo verde e/ou equivalentes. Neste nível alcançado pelas organizações deste tipo, deve ser considerada como uma exigência a ser "cobrada" das grandes organizações, cujas características socioambientais exigem tal posicionamento. É o caso das empresas pertencentes a setores econômicos como: papel e celulose; tabaco; farmacêutico; bebidas; química leve; e atividades correlatas de alto impacto socioambiental.

Indústrias de altíssimo efeito socioambiental (tipo J): o processo de avaliação dos impactos dos produtos, processos e instalações precisa ser sistematizado, buscando antecipar as questões públicas. A empresa necessita de certificação internacional do tipo selo verde e/ou equivalentes instituídos pela SA8000, AA1000 e congêneres. Deve adotar princípios de governança corporativa e cumpre padrões cumulativamente estruturados nos tipos de organização anteriormente descritos. São empresas como: petroquímica; química pesada; mineração; hidrelétricas; termoelétricas e usinas nucleares; cimento; fabricantes de agrotóxicos; produtoras de sementes transgênicas e atividades correlatas de altíssimo impacto socioambiental.

Fonte: Concepção dos autores

As organizações, a partir da análise dos dados primários dos questionários respondidos pelos gestores das empresas (serviços, comerciais e industriais), e das informações coletadas diretamente dos sites corporativos da amostra pesquisada, foram agrupadas em classes de acordo com a afinidade dos fatores socioambientais pesquisados, consoante descrição do Quadro 4. As empresas industriais foram desdobradas em quatro subcategorias (de $\mathbf{h}$ a $\mathbf{j}$ ) uma vez que as informações coletadas na pesquisa permitiram identificar, por exemplo, dentro das indústrias, organizações de altíssimo impacto ambiental, tais como: siderúrgicas, fábrica de cimento, indústria de papel e celulose, mineração, hidrelétricas e afins. 
Da mesma forma, montadoras do segmento automotivo, juntamente com organizações de autopeças, têxteis e confecções formaram, naturalmente, outro bloco de empresas, aqui denominado como empresas de médio efeito socioambiental.

Esta formação de blocos de empresas, assemelhadas entre si, tornou possível estabelecer correlações entre dados detalhados, obtidas através da aplicação do questionário da pesquisa, e informações esparsas coletadas diretamente dos sites das organizações da amostra.

Desta maneira, dados primários informados pelos respondentes das empresas do segmento de bebidas, puderam ser complementados por informações acessadas nos sites corporativos do segmento de tabaco. Ou seja, dada a natural correlação de cigarros e bebidas que, pela característica de ser um produto, por si só aético, derivou uma natural classe de indústrias de alto efeito socioambiental.

A caracterização de cada tipo de organização foi útil para sinalizar suas respectivas ações correspondentes, na forma de estratégias socioambientais, nos contornos delineados no presente trabalho. Esta tipologia permitiu estruturar uma arquitetura de dados de forma a agrupar, em um mesmo lócus virtual, informações de referência acerca da sustentabilidade empresarial.

\section{Base de dados socioambientais}

\subsection{Mapeamento da sustentabilidade empresarial}

Ficou evidente, pelos resultados da pesquisa, que uma organização, qualquer que seja seu estilo de gestão, possui "efeitos" socioambientais, que são diferenciados, em decorrência natural do setor econômico no qual esteja inserida. Esses efeitos, de acordo com o diagnóstico de sustentabilidade proposto neste trabalho (Quadro 5), podem ser representados na forma de passivo socioambiental. Para fazer frente a estes efeitos, a empresa necessita implementar ações compensatórias correspondentes, como contrapartida, na forma de deveres e obrigações (ativo socioambiental).

Quadro 5. Ativo e Passivo Socioambiental 


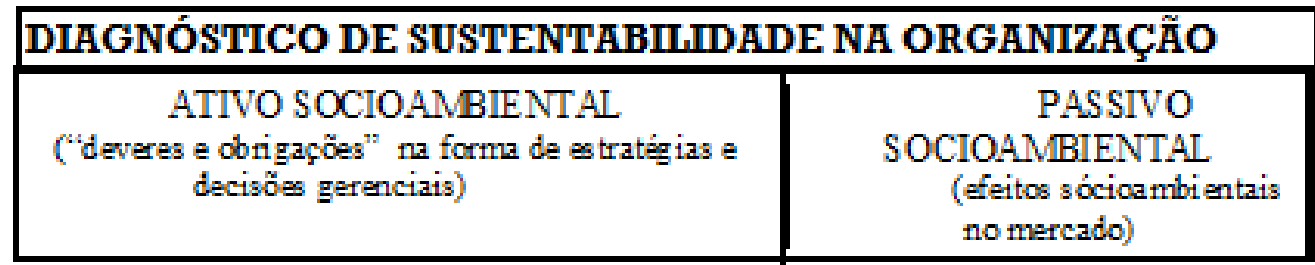

Fonte: concepção dos autores

Ou seja, o ativo seria o quanto de ações socioambientais seria necessário adotar, por iniciativa da direção da empresa, para preservar seus processos produtivos de forma sustentável. Seria o quanto de insumos produtivos e de providências gerenciais são necessárias para continuar a produzir, de forma sustentável, bens e serviços que consomem e absorvem recursos produtivos na forma de matérias-primas.

A analogia, simplificada, que se pode fazer é de uma pessoa de classe média, que possui carro para trabalhar. Esta pessoa, com seu carro, consome gasolina que emite gás carbônico, equivalente a uma árvore que teria que plantar, mensalmente, para compensar tal efeito ambiental nocivo. Neste raciocínio simplista, como há uma equivalência entre os efeitos socioambientais provocados pelo consumo mensal de gasolina (ônus socioambiental pela metodologia ora proposta) com a "compensação" na forma da árvore plantada, o confronto entre "passivo socioambiental" e "ativo socioambiental" seria zero. Ou seja, não há saldo favorável nem desfavorável do desempenho individual desta pessoa no contexto de sua vida privada.

Caso esta pessoa adotasse outras providências compensatórias como, além de plantar uma árvore por mês, por exemplo, instalasse um equipamento de gás veicular e adotasse transporte solidário, ela, certamente, teria um saldo socioambiental positivo a seu favor. $\mathrm{O}$ ativo socioambiental, teoricamente, seria maior que o passivo (efeitos socioambientais) provocado pela emissão de gás carbônico, agora reduzido pelo consumo alternativo de gás veicular ao invés da gasolina.

Fazendo uma analogia com o cenário empresarial, seria como se contentar com o levantamento de emissão e das projeções de neutralização de carbono, via plantação de mudas de árvores. Para calcular o impacto total do mundo dos negócios, devem ser somados os efeitos socioambientais de todo universo empresarial. Quanto maior for o mundo empresarial, 
menor será a quantidade de ativo socioambiental disponível por empresa. Como o consumo de insumos produtivos por parte das empresas estaria ocorrendo numa velocidade maior que a capacidade de reposição, significa que a continuidade das organizações está sob risco econômico de sobrevivência, à longo prazo.

Este diagnóstico socioambiental, coerentemente com os fatores de análise da sustentabilidade pesquisados (Quadros 1 e 2), pode ser representado na forma de um balanço de sustentabilidade.

\subsection{Arquitetura do balanço de sustentabilidade}

A proposta de balanço (de sustentabilidade ou socioambiental) está centrada na formulação de um indicador de desenvolvimento socioambiental - IDS que refletiria o estágio em que se encontra a organização em termos de sustentabilidade.

É coerente com o que preceitua o Conselho Econômico Social das Nações Unidas (1991), para que as empresas façam uma internalização das externalidades negativas, que representariam os impactos causados ao meio ambiente, no sentido de calcular-se um custo ambiental completo. Segundo as Nações Unidas, o passo inicial a ser superado consistiria em separar as despesas ambientais de outras despesas e, objetivamente, mensurar o passivo ambiental das empresas. Essa individualização das despesas ambientais favoreceria a apresentação de demonstrativos em termos de custeio dos efeitos ambientais causados pelas organizações. Permitiria, ainda, avaliar os investimentos que poderiam ser provisionados e alocados nos demonstrativos contábeis, não-tradicionais (mensuração dos efeitos ambientais).

A proposta do presente trabalho, que foi socioambiental, agregou aos impactos ambientais, também, os efeitos em termos de responsabilidade social (accountability), no âmbito das organizações. Foi estruturada em dois estágios de análise para se chegar aos valores dos indicadores de desenvolvimento socioambiental - IDS e correspondente balanço de sustentabilidade.

Em um primeiro estágio foi feito o diagnóstico socioambiental das empresas pesquisadas, onde foram analisadas as dimensões de sustentabilidade da cadeia produtiva, transparência em termos de evidenciação externa, governança corporativa, e capital humano (qualidade de vida no trabalho). 
A emissão desse balanço observaria enfoques diferenciados de sustentabilidade para diferentes organizações que, em razão de seu ramo de negócios, sofrem efeitos socioambientais distintos (vide Quadro 6).

Quadro 6. Estrutura do Balanço Socioambiental

\begin{tabular}{|c|c|}
\hline \multicolumn{2}{|c|}{ BALANÇO SOCIOAMBIENTAL } \\
\hline $\begin{array}{c}\text { ATIV0 } \\
\text { Onus empresariais(apropriação de custos) }\end{array}$ & $\begin{array}{c}\text { PASSIV0 } \\
\text { Efeitos socioambientais }\end{array}$ \\
\hline $\begin{array}{l}\text { Sustentabilidade } \\
\text { 1. ABNT / ISO } 14.000 \\
\text { 2. ABNT / ISO } 16.000 \\
\text { 3. SA } 8000 \text { / AA } 1000\end{array}$ & $\begin{array}{l}\text { Sustentabilidade } \\
\text { Exigência de sua cadeia produtiva } \\
\text { ( fornecedores, clientes, governo, ...) }\end{array}$ \\
\hline \begin{tabular}{l}
\multicolumn{1}{c}{ TRANSPARÉNCIA } \\
4. Balanço social (Ethos, Akatu, GRI, etc.) \\
5. Código de 'ética implementado
\end{tabular} & \begin{tabular}{l}
\multicolumn{1}{|c|}{ TRANSPARÉNCIA } \\
Evidenciação externa dos resultados da gestão \\
junto aos publicos de interesse
\end{tabular} \\
\hline $\begin{array}{l}\text { GOVERNANCA CORPORATIVA } \\
\text { 6. Nível } 1,2,3 \text { ou } 4 \\
\text { 7. Novo mercado(ou ISE/DJSI) }\end{array}$ & $\begin{array}{l}\text { GOVERNANCA CORPORATIVA } \\
\text { Boas praticas de governanca junto ao publico } \\
\text { (acionistas, instituições financeiras, etc.) }\end{array}$ \\
\hline $\begin{array}{l}\text { CAPITAL HUMANO } \\
\text { 8. programa de clima organizacional } \\
\text { 9. plano de carreira } \\
\text { 10. remuneracao estratégica }\end{array}$ & $\begin{array}{c}\text { CAPITAL HUMANO } \\
\text { Exigências de seus processos de gestão e QVT }\end{array}$ \\
\hline
\end{tabular}

Fonte: Concepção dos autores

O balanço de sustentabilidade evidenciaria, de um lado, os efeitos socioambientais gerados pela organização (fatores de análise do Quadro 1 e 2 são quantificados, a priori, como passivo), e de outro, as decisões de sustentabilidade empresarial da sua Administração, com os correspondentes ônus econômico (custos socioambientais apurados, a posteriori, como ativo) para fazer frente às exigências decorrentes das operações empresariais.

Dessa maneira poder-se-ia registrar e mensurar custos socioambientais de uma determinada organização, bem como o comportamento de organizações pertencentes a um mesmo setor econômico. 
Nesta proposta de balanço de sustentabilidade, foram considerados quatro grupos de elementos de custeio (passíveis de adaptações eis que o modelo adotado não é, rigidamente, prescritivo). No primeiro grupamento de custeio de sustentabilidade, foram considerados os parâmetros de análise (ABNT/ISO14000, ABNT/ISO16000, AA1000, SA8000 e equivalentes) de cidadania corporativa. Em outra dimensão de análise - transparência considerou-se a existência de publicação de balanços sociais e/ou de relatórios de sustentabilidade utilizados pelas empresas.

Foi considerado, também, a adoção de código de ética, compartilhado pelos colaboradores da organização, em todos seus níveis hierárquicos e, principalmente, nas interações com os diferentes públicos que interagem com a empresa. E, como outro grupo de elementos de custeio, a governança corporativa, fundamentado nos conceitos do Instituto Brasileiro de Governança Corporativa - IBGC e da Bolsa de Valores de São Paulo (BOVESPA, 2008) que consideram um ranking de empresas classificadas como de nível 1, nível 2, novo mercado e índice de sustentabilidade empresarial - ISE.

No grupo capital humano, considerou-se o conceito de "riqueza criada por empregado" (Melhores \& Maiores da Revista Exame, 2008). Esse conceito, relaciona o total da riqueza criada pela empresa pela média aritmética do número de empregados, sem levar em conta, eventuais serviços terceirizados (indica a produtividade dos trabalhadores e a contribuição média de cada um na riqueza gerada pela empresa). Essa relação serviria para evidenciar a produtividade da mão-de-obra no contexto interno das empresas pesquisadas.

Nessa visão do balanço socioambiental pode ser exemplificada a situação de uma hidrelétrica do tipo J, que é uma organização de altíssimo efeito socioambiental. O Passivo, que deve ser o espelho da tipologia estabelecida no Quadro 4, enquanto o Ativo deve representar o quanto de ações de sustentabilidade a organização necessita adotar, face seus efeitos socioambientais, é exemplificado no Quadro 7 explicitado a seguir. Neste exemplo (Quadro 7) existe uma significativa defasagem entre o que seria exigido, normalmente, para uma empresa de altíssimo efeito socioambiental e o que é adotado de práticas compensatórias desses impactos provenientes das peculiaridades dessa organização.

Quadro 7 - Exemplo de aplicação de Balanço Socioambiental 


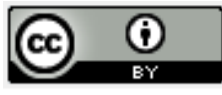

\begin{tabular}{|c|c|c|}
\hline $\begin{array}{c}\text { ATIVO } \\
\text { (ônus empresarial, base para apropriação dos custos) }\end{array}$ & $\begin{array}{c}\text { Assin } \\
\operatorname{alar} \\
\operatorname{com} X\end{array}$ & $\begin{array}{c}\text { PASSIVO } \\
\text { (efeitos socioambientais) }\end{array}$ \\
\hline $\begin{array}{l}\text { 1. Sustentabilidade e Governança corporativa: } \\
\text { 1.1. norma ambiental (ISO14000) } \\
\text { 1.2. norma de responsabilidade social(ISO16000, } \\
\text { SA8000, AA1000, GRI,) } \\
\text { 1.3.governança (IBGC, Bovespa; índice Dow Jones de } \\
\text { Sustentabilidade-ISE). }\end{array}$ & $\begin{array}{c}\mathbf{0 , 0 8} \\
\mathrm{X} \\
\mathrm{X}\end{array}$ & $\begin{array}{l}\text { Comunidade e diferentes públicos externos carentes } \\
\text { de uma melhor imagem social } \\
\text { Acionistas carentes de informações sobre o } \\
\text { desempenho da empresa. }\end{array}$ \\
\hline $\begin{array}{l}\text { 2.Capital humano } \\
\text { 2.0. treinamento e desenvolvimento } \\
\text { 2.1.colaboradores } \\
\text { 2.2. clientes } \\
\text { 2.3. fornecedores } \\
\text { 3. planejamento de carreira } \\
\text { 3.1. alta administração } \\
\text { 3.2. nível operacional } \\
\text { 3.3. integração com treinamento e avaliação desempenho } \\
\text { 4. plano de cargos, salários e benefícios } \\
\text { 4.1. remuneração variável } \\
\text { 4.2. participação nos resultados } \\
\text { 4.3. integração com treinamento }\end{array}$ & $\begin{array}{c}\mathbf{0 , 1} \\
\\
\mathrm{X} \\
\mathrm{X} \\
\mathrm{X} \\
\mathbf{0 , 0 6} \\
\mathrm{X} \\
\mathrm{X} \\
\mathrm{X} \\
0,03 \\
\mathrm{X} \\
-\end{array}$ & $\begin{array}{l}\text { Empresa cl atividade econômica de altíssimo } \\
\text { impacto ambiental (de seus processos produtivos e } \\
\text { instalações). Alto grau automação nos controles de } \\
\text { geração e distribuição de energia. Cadeia produtiva } \\
\text { de efeitos socioambientais a serem monitorados } \\
\text { junto a fornecedores e clientes }\end{array}$ \\
\hline $\begin{array}{l}\text { 5. Gestão de talentos } \\
\text { 5.1. recrutamento via Internet } \\
\text { 5.2. banco de dados de RH } \\
\text { 5.3. suporte de TIs } \\
\text { 6. configuração organizacional } \\
\text { 6.1. estrutura matricial / por projetos } \\
\text { 6.2. organização por processos } \\
\text { 7. programas de clima organizacional } \\
\text { 7.1. pesquisas sistemáticas } \\
\text { 7.2. pesquisas esporádicas } \\
\text { 8. ações sociais } \\
\text { 8.1. diversidade racial } \\
\text { 8.2. voluntariado } \\
\text { 9. Transparência e ética } \\
\text { 9.1. balanço social } \\
\text { 9.1. relatório socioambiental }\end{array}$ & $\begin{array}{c}\mathbf{0 , 0 5} \\
- \\
- \\
X \\
0,05 \\
\\
- \\
0,01 \\
X \\
0,08 \\
X \\
0,09 \\
X \\
X\end{array}$ & $\begin{array}{l}\text { - empresas com emprego intensivo de mão-de-obra; } \\
\text { - condições precárias de higiene e segurança do } \\
\text { trabalho. } \\
\text { - trabalho interno com má qualidade de vida. }\end{array}$ \\
\hline $\begin{array}{l}\text { 10. postura ética } \\
\text { 10.1.código de ética para clientes / fornecedores } \\
\text { 10.2. código de ética para relacionamento com governos }\end{array}$ & $\begin{array}{l}0,1 \\
\mathrm{X} \\
\mathrm{X}\end{array}$ & $\begin{array}{l}\text { - exigência da legislação que regula a atividade } \\
\text { econômica } \\
\text { - interação com governo nas esferas municipal, } \\
\text { estadual e federal }\end{array}$ \\
\hline
\end{tabular}

Fonte: Concepção dos autores 
Efetuando-se o somatório das métricas (coluna central onde a incidência é assinalada com $\mathbf{X}$ ) dos dez fatores de influência (soma no nível do sub-total dos elementos do Balanço) tem-se:

$$
0,08+0,10+0,06+0,03+0,05+0,05+0,01+0,08+0,09+0,10=0,65
$$

$\mathrm{Na}$ interpretação do IDS da empresa, neste segundo estágio de análise, de acordo com a premissa do modelo, quanto maior melhor, foi estruturada uma tabela de análise, decorrência das inferências dos dados coletados na pesquisa, na forma de base de dados de IDS (vide detalhamento na Tabela 2). Esta tabela evidencia as empresas do universo empresarial brasileiro, classificadas por setor econômico, de forma apriorística (com padrões de IDS variando em intervalos pré-estabelecidos), a partir dos fatores analisados do passivo ambiental. A métrica, singular a cada tipo de organização analisada, apurada a posteriori, a partir do cumprimento dos quesitos estabelecidos como ativo ambiental, pode variar nos intervalos do IDS de cada setor econômico. Empresas do tipo A, por exemplo, tiveram os valores de IDS variando de 0 a 1; as do tipo 2 com valores no intervalo entre 1,1 a 2,0 e assim sucessivamente até as empresas do tipo $J$, com valores variando de 9,1 a 10 .

Tabela 2 - Tipologia de empresas e métricas de IDS

\begin{tabular}{|l|c|}
\hline \multicolumn{1}{|c|}{ TIPOLOGIA DA MPRESA } & VALORES DE IDS \\
\hline TIPO A; organizações sociais & 0 a 1 \\
\hline TIPO B; empresas prestadores de serviços & 1,1 a 2 \\
\hline TIPO C; empresas comerciais & 2,1 a 3 \\
\hline TIPO D; instituições financeiras & 3,1 a 4 \\
\hline TIPO E; hospitais e hotelaria & 4,1 a 5 \\
\hline TIPO F; empresas de médio efeito socioambiental & 5,1 a 6 \\
\hline TIPO G; empresas produtoras de bens não-duráveis & 6,1 a 7 \\
\hline TIPO H; empresas produtoras de bens duravéis & 7,1 a 8 \\
\hline TIPO I; indútrias de alto efeito socioamniental & 8,1 a 9 \\
\hline TIPO J; indústria de altissímo efeito socioambientalo & 9,1 a 10 \\
\hline
\end{tabular}

Fonte: Concepção dos autores

No exemplo (Quadro 7), a hidrelétrica se enquadra em uma organização do tipo J de altíssimo impacto ambiental. Portanto, seu IDS deve variar entre os valores estipulados de IDS, da Tabela 2, entre 9,1 (valor mínimo) a $\mathbf{1 0}$ (valor máximo). No caso ilustrativo, obtevese um indicador de desenvolvimento socioambiental de 9,65; apurado somando-se:

$$
9,0+0,65=9,65
$$




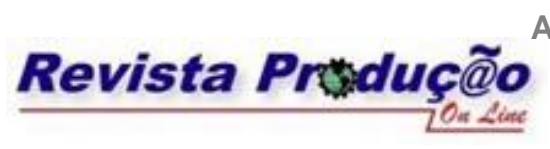

Associação Brasileira de Engenharia de Produção - ABEPRO

Universidade Federal de Santa Catarina - UFSC

www.producaoonline.org.br

ISSN 1676 - 1901 / Vol. IX/ Num.IV/ 2009

(c)

Ou seja, o "indicador de desenvolvimento socioambiental" sinaliza que a organização carece, ainda, de uma evolução rumo a uma plena gestão socioambiental representado por um IDS ideal de 10. Este indicador recomendado é pertinente apenas para as empresas pertencentes ao setor econômico de indústrias de altíssimos efeitos socioambientais, conforme sugerido pelo presente trabalho.

A modelagem lógica da base de dados (vide Figura 2), conceitualmente especificado como Sistema Informatizado de Monitoramento Ambiental e de Sustentabilidade Empresarial - SIMASE, foi estruturada em quatro níveis de análise para se chegar aos valores dos indicadores de desenvolvimento socioambiental - IDS e correspondente balanço socioambiental. No primeiro nível foi feito o diagnóstico socioambiental onde foram analisadas as dimensões de sustentabilidade, transparência, governança corporativa, e capital humano. Em um segundo nível, foi estruturada a base de dados de IDS das empresas do universo empresarial brasileiro, classificadas por setor econômico, de forma apriorística (com padrões de IDS variando em intervalos pré-estabelecidos), a partir dos fatores analisados do passivo ambiental. No terceiro nível, foram concebidos os recursos computacionais para geração do balanço socioambiental e, principalmente, de parâmetros de recuperação das informações de sustentabilidade.

Figura 2. Representação da estrutura de programas do software SIMASE 


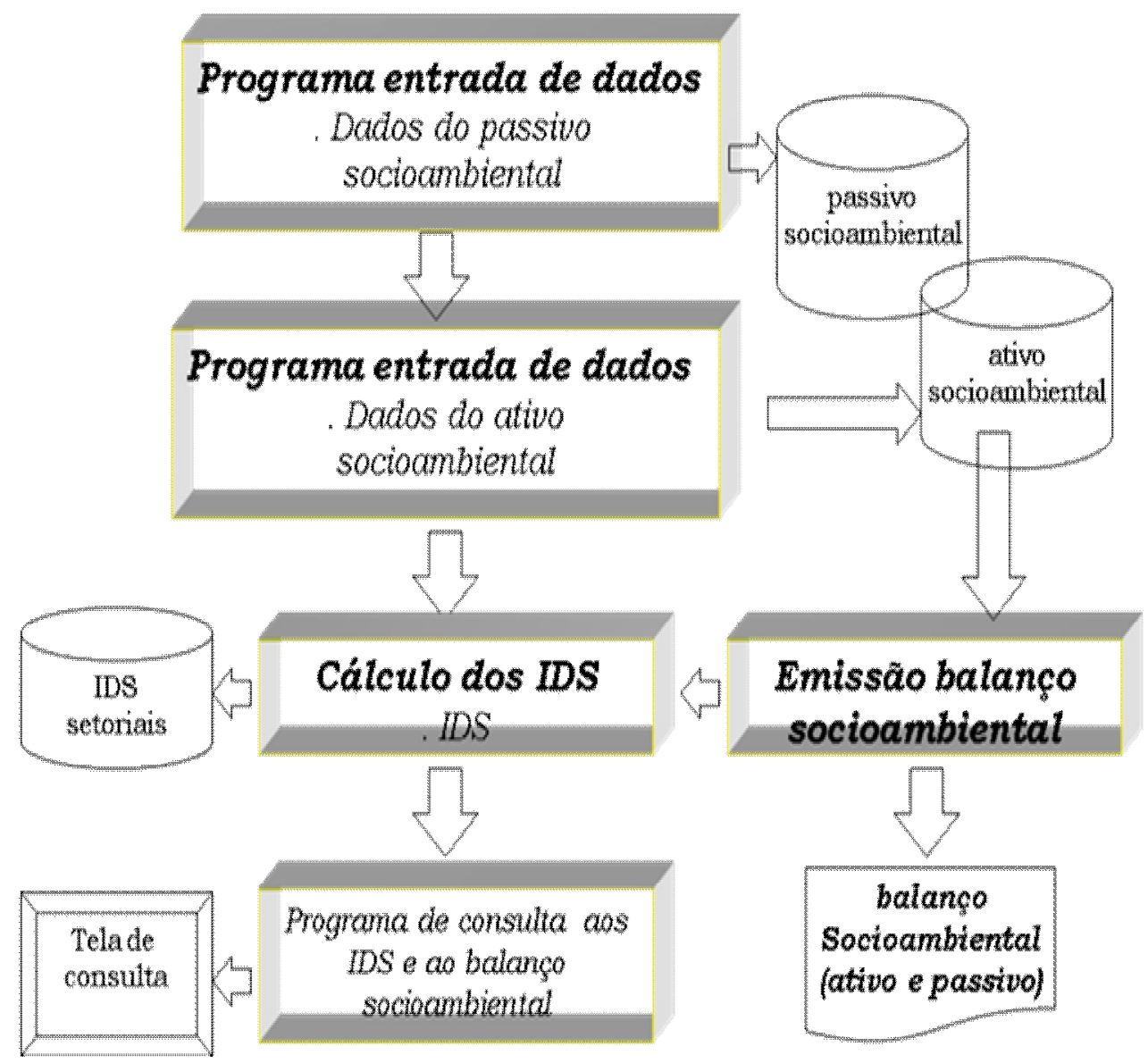

Fonte: concepção dos autores

E, no quarto nível, foi criado o software de interface com o usuário, para permitir buscas, consultas e acesso on-line aos dados armazenados pelo sistema (balanço socioambiental, indicadores e demais informações de sustentabilidade).

Em termos de programação e desenvolvimento de software, a modelagem da base de dados poderia ser explicitada conforme ilustração dessa Figura 2. Essa possibilidade computacional, sistematizada no Sistema Informatizado de Monitoramento Ambiental e de Sustentabilidade Empresarial - SIMASE, é meramente um referencial para outras alternativas de desenvolvimento sistêmico.

A emissão desse balanço ocorre nesse quarto nível, observando enfoques diferenciados de sustentabilidade para diferentes organizações que, em razão de seu ramo de 


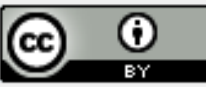

negócios, sofrem efeitos socioambientais distintos (Quadro 4). Nesse quarto nível seria gerada analiticamente, ainda, tela de consulta, por empresa, conforme exemplificada graficamente na figura 3, para uma empresa hipotética "Alpha S/A”. Nela, são evidenciadas informações que caracterizam a empresa (denominação da empresa, setor econômico e IDS) e aquelas inerentes ao cumprimento dos quesitos inerente ao ativo socioambiental.

Figura 3. Representação da Tela de Consultas Customizada por Empresa

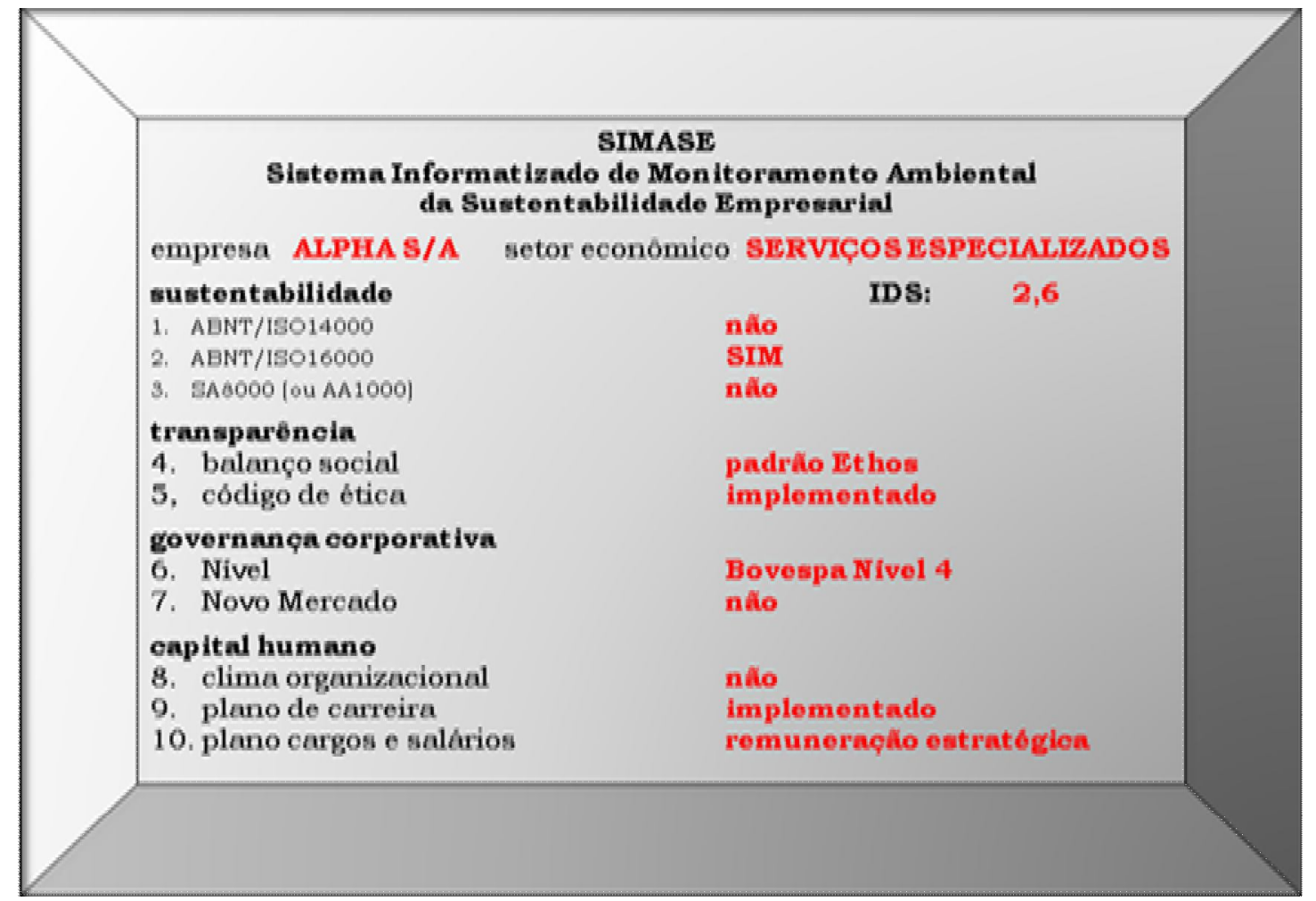

Fonte: concepção dos autores

Fazendo uma análise das informações de sustentabilidade (tela de consultas da Figura 3), e comparando-a com outras organizações concorrentes do mesmo setor econômico (benchmarking), podem ser estabelecidas ênfases de estratégias ambientais e sociais específicas para a empresa focalizada. Isto permitiria criar condições para o aprimoramento das práticas empresariais corporativas na medida em que as estratégias de negócios passariam a se apoiar cada vez mais em metas de sustentabilidade. 
Ou seja, dada a convergência com os objetivos corporativos, as informações de sustentabilidade de uma base de dados, possibilitariam que as empresas definam qual a melhor estratégia para a geração de valor, explorando o potencial de crescimento econômico, de forma integrada com suas ações socioambientais.

\section{CONCLUSÕES}

O objetivo deste trabalho foi conceber uma arquitetura de base de dados para subsidiar o monitoramento e direcionamento da gestão socioambiental nas empresas. Ela sinalizaria os requisitos necessários para o processo de tomada de decisões de sustentabilidade, de forma convergente com os objetivos estratégicos da organização.

Tal modelo sugere que sejam adotados enfoques distintos de gestão para diferentes tipos de organizações que, em razão de seu ramo de negócios, sofrem efeitos socioambientais diferenciados.

Além de refletir o estágio de sustentabilidade em que se encontra a empresa analisada, a arquitetura permitiria o mapeamento socioambiental dos diferentes segmentos econômicos do universo empresarial brasileiro.

O modelo sugerido partiu do pressuposto de que os resultados corporativos passam a depender cada vez mais de decisões empresariais que levem em conta que: a) não há conflito entre lucratividade e a questão socioambiental; b) clientes e comunidade passam a valorizar cada vez mais a proteção do meio ambiente; c) a demanda e, portanto, o faturamento das empresas sofre crescentes pressões e depende diretamente do comportamento de consumidores que enfatizarão suas preferências para produtos e organizações eticamente corretas.

Outros resultados específicos, decorrentes da implementação dessa arquitetura, poderiam ser obtidos quanto à evidenciação externa, com oportunidade e clareza, possibilitando a perfeita compreensão, por parte dos stakeholders, da verdadeira situação que se encontra a organização. Ou seja, dados decorrentes do balanço de sustentabilidade e mesmo do IDS apurado, poderiam fazer parte do Relatório da Administração, que acompanha 


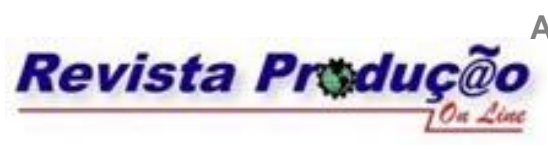

Associação Brasileira de Engenharia de Produção - ABEPRO

Universidade Federal de Santa Catarina - UFSC

www.producaoonline.org.br

ISSN 1676 - 1901 / Vol. IX/ Num.IV/ 2009

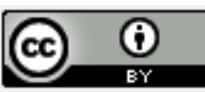

as demonstrações financeiras - DFs, e do próprio balanço social, normalmente, divulgado pela empresa.

\section{REFERÊNCIAS BIBLIOGRÁFICAS}

BESSERMAN, Sérgio. A Lacuna das informações ambientais. In: TRIGUEIRO, André (Coord.). Meio Ambiente no século 21. Rio de Janeiro: Sextante, 2003.

BOLSA DE VALORES DE SÃO PAULO. BOVESPA. São Paulo, 2008. Disponível no site www.bovespa.com.br, Acesso em: 30 abr. 2008.

BRONN P. S.; VRIONI, A. B. Corporate social responsibility and cause-related marketing: an overview. International Journal of Advertising, n.20, n.2, 2001.

BUYTENDIJK, F.; WOOD, B.; GEISHECKER, L. Mapping Road to Corporate Performance Management. Gartner Group, January, 2004.

DRAPER, S. W.; DUNLOP, M.D. New IR-New Evaluation: the impact of interaction and multimedia on information retrieval and its evaluation,2002. Disponível em: http://www.cs.strath.ac.uk/ mdd/research/publications/nrhm/new_IR_new_eval.pdf. Acesso em: 30 abr. 2008.

EVANS, P.; WÜRSTER, T. Blown to Bits: How the Economics of Information Transforms Strategy, Boston. Harvard Business School Press, 2000.

GLASER, B.; STRAUSS, A. The Discovery of Grounded Theory, Chicago: Aldine, 1967.

GLASER, B. Doing grounded theory: issues and discussions. Mill Valley, Ca.: Sociology Press, 1998.

GLASER, B.; HOLTON, J. Remodeling Grounded Theory. The Grounded Theory Review. V.4, n.1, November 2004.

HENDERSON, H. Transcendendo a economia. Tradução de Merle Scoss. 10a ed. São Paulo: Editora Cultrix, 2001.

INSTITUTO BRASILEIRO DE GEOGRAFIA E ESTATÍSTICA - IBGE. Indicadores de desenvolvimento sustentável - Brasil. Brasília: IBGE, 2008.

INSTITUTO BRASILEIRO DE ANÁLISES SOCIAIS E ECONÔMICAS. Guia de Balanço Social - IBASE. Disponível em www.ibase.org.br. Acesso em: 01 mai. 2008. 
INSTITUTO ETHOS DE RESPONSABILIDADE SOCIAL. Matriz de Evidências de Sustentabilidade, Banco de Práticas e Ferramentas de gestão: Indicadores Ethos, Guia de Elaboração de Balanço Social. Disponível em www.ethos.org.br. Acesso em: 01 mai. 2008.

LAUDON, K.C.; LAUDON, J.P. Management information systems: organization and technology in the networked enterprise. New Jersey: Prentice-Hall, 2000.

NAÇÕES UNIDAS - Conselho Econômico Social. Centro de lãs Naciones Unidas sobre las Empresas Transnacionales. Questões relacionadas com La contabilidad y La presentación de informes a nível internacional: examen de 1990. New York, 1991.

ONU - Organização das nações Unidas. Contabilidad financiera y presentación de informes ambientales por las empresas. http://www.unetad.org/sp/sphome.htm. Acesso em 15 nov. 2007.

ORGANIZATION FOR ECONOMIC CO-OPERATION AND DEVELOPMENT. OECD Core set of Indicators for Environmental Performance Reviews. A synthesis report by the Group on the State of the Environment. Environment Monographs $N^{\circ}$ 83. Paris: OECD, 1993. Disponível em: http://lead.virtualcentre.org/en/dec/toolbox/Refer/gd93179.pdf. Acesso em 30 abr. 2008.

PROGRAMA DAS NAÇÕES UNIDAS PARA O DESENVOLVIMENTO. Relatório de Desenvolvimento Humano 2007/2008: Combater as alterações climáticas: Solidariedade humana num mundo dividido. PNUD, UN Plaza, New York, 2007. Disponível em: http://www.pnud.org.br/arquivos/rdh/rdh20072008/hdr_20072008_pt_complete.pdf. Acesso em: 01 fev 2008.

RAYNARD, P.; FORSTARTER, M. Corporate Social Responsibility: Implications for Small and Medium Enterprises in Developing Countries. United Nations Industrial Development Organization, Viena, 2002. Disponível em: http://www.unido.org/doc/5162. Acesso em 01 fev. 2008.

REVISTA EXAME. Melhores e Maiores e As Melhores Empresas em Cidadania Corporativa, São Paulo. Editora Abril, 2008.

STRAUSS, A.; CORBIN, J. Grounded Theory Methodology - An Overview. Handbook of Qualitative Research, N.K. Denzin and Y.S. Lincoln (eds.), Sage Publications, Thousand Oaks, CA, 1994. 


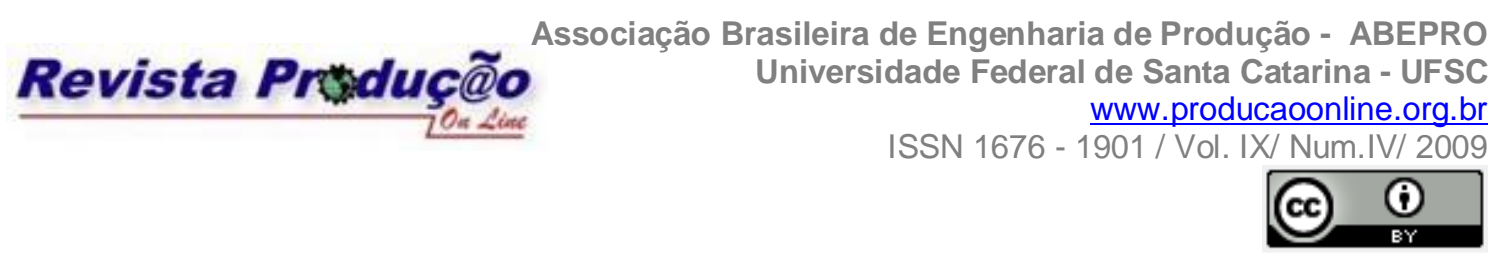

STRAUSS, A.; CORBIN, J. Grounded Theory in Practice, Sage Publications, London, 1997.

TACHIZAWA, T. Gestão Ambiental e Responsabilidade Social Corporativa. $6^{\mathrm{a}}$. edição revista e ampliada. São Paulo: Editora Atlas, 2009.

TACHIZAWA, T. e ANDRADE, R. O. B. Gestão Socioambiental: estratégias na nova era da sustentabilidade. São Paulo: Campus Elsevier, 2008.

Artigo recebido em 31/05/2009 e aceito para publicação em 15/12/2009. 